\title{
Incorporating temperature-driven seasonal variation in survival, growth, and reproduction into population models for small fish
}

\author{
Sandy Raimondo* \\ US Environmental Protection Agency, Gulf Ecology Division, 1 Sabine Island Drive, Gulf Breeze, Florida 32561, USA
}

\begin{abstract}
Seasonal variation in survival and reproduction can be a large source of prediction uncertainty in models used for conservation and management. A seasonally varying population model is developed that incorporates temperature-driven differences in mortality and reproduction for the small fish species the sheepshead minnow Cyprinodon variegatus. A temperaturedependent growth rate function is developed for the von Bertalanffy constant, $K$, measured at various temperatures and fit to a logistic curve. The value of $K$ at each temperature estimates the duration of mobile life stages. Stage-specific mortality is modeled as a power function of size that includes a temperature-dependent modification for extraneous ecological factors such as predation. Seasonal reproduction is described through temperature-dependent functions of embryo survival and stage duration. Model sensitivity analysis indicates that the largest influence on the population growth rate is $K$. Cessation of reproduction at lower temperatures is also a critical driver of population growth rate. Population projections used either seasonal or constant parameters for 16 hypothetical populations and demonstrated the potential for long-term error propagation in population projection using constant rates. Models used for conservation and management should employ realistic temporal resolution that will allow for seasonal effects of temperature on growth, reproduction, and survival to be incorporated into population projections.
\end{abstract}

KEY WORDS: Temperature $\cdot$ Growth $\cdot$ Mortality $\cdot$ Reproduction $\cdot$ Fish $\cdot$ Population dynamics Seasonal variation

Resale or republication not permitted without written consent of the publisher

\section{INTRODUCTION}

Seasonal variation in natural mortality and reproduction is well documented for fish species (Nordlie 2000, Shoji \& Tanaka 2007, Buckley et al. 2010). With the exception of overwinter mortality for commercially important stocks (e.g. Carlson et al. 2008), annualized survival rates that assume average seasonal conditions prevail in models pertaining to management decisions, particularly for nongame species. General models for estimating rates of natural mortality in fish derive an annual rate based on longevity, mean temperature, size, and growth rate (Pauly 1980, Djabali et al. 1993, Hewitt \& Hoenig
2005, Gislason et al. 2010). There is little evidence that these relationships are useful for describing intra-specific variation in mortality associated with seasonal changes (Bevacqua et al. 2011). Specifically, short-lived species or those with overlapping generations may have high variability in growth rates and mortality from seasonal temperature fluctuations, which may have an important influence on their population dynamics (Conover \& Present 1990, Rice et al. 1993). Annual demographic rates based on peak season or average estimates may not adequately describe important impacts on small fish species. Moreover, the sensitivity of population projections to this temporal variability has not been 
thoroughly evaluated in small marine or estuarine fishes.

Temperature, size, growth rate, and life-stage duration are covariates of cohort-specific mortality that are themselves correlated (Miller et al. 1988, Griffiths \& Harrod 2007, Gislason et al. 2010), and due to their interactions their overall effect on mortality is complex. Higher temperatures increase mortality both directly and indirectly. Directly, temperature increases fish growth rate which can result in higher mortality from increased energetic costs (Savage et al. 2004, McCoy \& Gillooly 2008). Indirectly, small fish in warmer water are at greater risk of predation because predators eat more to meet higher metabolic demands, which has been demonstrated both geographically (Pauly 1980) and seasonally (Buckley et al. 2010). Conversely, faster growth rates can reduce mortality by decreasing the duration of vulnerable life stages (Takasuka et al. 2004). Moreover, larger fish have lower mortality as a result of reduced predation pressures (Anderson 1988). All of these relationships have been well documented through analysis of diverse species datasets (Pauly 1980, Lorenzen 1996, Griffiths \& Harrod 2007, Gislason et al. 2010), simulation modeling (Rice et al. 1993, Cowan et al. 1996), otolith analysis (Takasuka et al. 2004, Meekan et al. 2006, Shoji \& Tanaka 2007, Durieux et al. 2009), and experimentation (Thompson et al. 1991, Brunton \& Booth 2003).

The influence of temperature and size in isolation have opposing effects on mortality, and have been proposed to cancel each other out (Pepin 1991). However, when operating concurrently, the interaction between these 2 factors may introduce a more complicated relationship. Significant effects of both variables on mortality have been measured when both are present (Griffiths \& Harrod 2007, McCoy \& Gillooly 2008), and their relative contribution to mortality has been extensively explored in case studies (e.g. Hare \& Cowen 1997, Takasuka et al. 2004, Meekan et al. 2006, Islam et al. 2010). Both are critical factors of mortality, and the interaction between them should be considered quantitatively when estimating natural mortality of fishes (Griffiths \& Harrod 2007, McCoy \& Gillooly 2008).

Limited attention has been given to methods that allow these relationships to be incorporated into population models for fish, despite the importance of capturing this source of variability. While seasonal variation in survival has been measured in fish (Carlson et al. 2008, Letcher \& Horton 2008), incorporating such seasonal dynamics into models has been limited to birds (Etterson et al. 2009) and invertebrates
(Levin \& Huggett 1990, Dobson et al. 2011). The present study presents a simple approach for incorporating temperature-dependent variability of demographic rates into matrix models that reflect the influences of seasonality. The basis of the approach are functions of mortality and reproduction that are dependent on temperature, growth rate, size, and stage duration using the sheepshead minnow Cyprinodon variegatus Lacepède as a model fish species. While these functions could be incorporated into other model structures that are more flexible for modeling complex dynamics, such as individualbased models (IBMs) or integral projection models, a stage-based matrix model was used here because they are frequently selected for their simplicity and applied in management contexts (e.g. Morris et al. 2011). The objectives of the present work were to: (1) model the complex relationship between temperature, growth, and survival for small fish with the endpoint of stage-specific survival; (2) demonstrate the incorporation of this dynamic process into an example model construct that also contains seasonally varying reproduction; and (3) evaluate the sensitivity of model outcomes to these interactions.

\section{METHODS}

\section{Sheepshead minnow demography}

The sheepshead minnow Cyprinodon variegatus (Cyprinodontidae) is a small euryhaline fish found in coastal bays and estuaries throughout the east and Gulf coasts of the United States and Mexico and may be one of the most abundant fish species in some estuarine marshes. The species is a standard toxicity test organism that has been used regularly for toxicity assessments for several decades (Hansen \& Parrish 1977). The abundant toxicity information on this species makes it a good candidate for use in population-level risk assessments; however, the majority of recently published studies report laboratory-based demographic rates with limited connection to natural populations. The demography used in the model described here is based on conformance of recently published laboratory studies and earlier field and natural history studies (e.g. Rowe \& Dunson 1995, Cripe et al. 2009).

The sheepshead minnow life cycle is composed of 4 life stages indexed by $i=1,2,3$, and 4 representing embryo (within egg), larva (hatchling to development of swim bladder), juvenile (through sexual maturation), and adult, respectively. While transitions 
between fish life stages may be triggered by size, age, or environment, the model for this species assumes that size is the most dominant of these influences on maturation based on agreement of maturation sizes from different locations (Kinne \& Kinne 1962, Warlen 1964, Hardy 1978, Nordlie 2000, Cripe et al. 2009). The average size of fish at the larvaljuvenile and juvenile-adult life-stage transitions are 1.5 and $2.6 \mathrm{~cm}$, respectively (Nordlie 2000, Cripe et al. 2009), which were chosen to define the sizes of the life stages in this model. Adult sizes range from $>2.6$ to approximately $5.5 \mathrm{~cm}$.

\section{Temperature-dependent mortality}

Seasonality is modeled as a function of environmental temperature, which is considered to be the primary environmental influence. Temperature negatively affects survival through increased predation and positively influences growth. Increased growth rate negatively affects survival through increased energetic demands. Increased growth reduces stage duration and increases size. Larger sizes and shorter life-stage duration increases the probability of stagespecific survival (Fig. 1). All of these relationships are modeled below, with the following exceptions: the influence of growth rate on the duration of the adult stage is considered negligible, since adults of this species live up to $3 \mathrm{yr}$, and the potential for increased mortality associated with elevated energetic demands of higher growth rates is excluded based on the assumption that self-sustaining populations within their native ranges are physiologically adapted to the

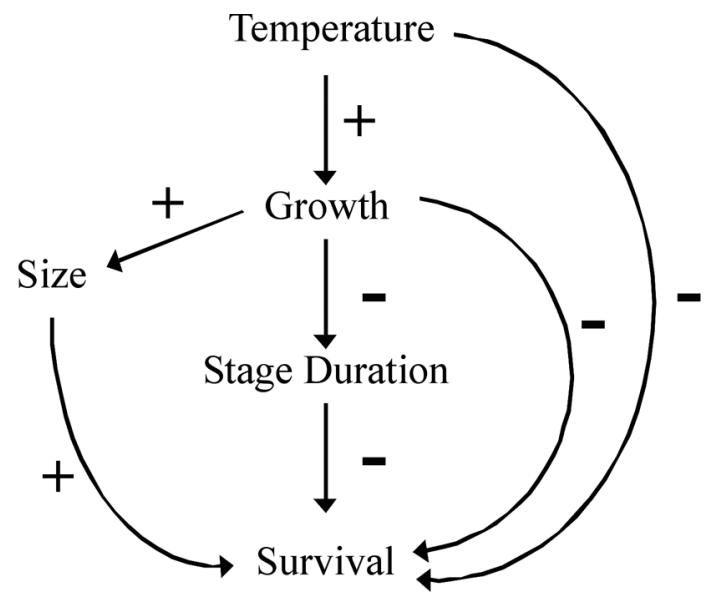

Fig. 1. Cyprinodon variegatus. The relationship of temperature, growth, size, and life stage duration on stage-specific survival. Plus and minus signs associated with arrows between 2 factors indicate where an increase in the first variable increases or decreases the second seasonal variation in environmental conditions (Carlson et al. 2008), so implications of seasonal metabolic changes should be negligible.

The influence of seasonal temperature on survival is initiated by a temperature-dependent growth rate function. The growth of sheepshead minnow fed ad libitum was measured over $6 \mathrm{wk}$ at various temperatures $\left(15,20,25,30\right.$, and $35^{\circ} \mathrm{C}$; Berry 1987) and for $653 \mathrm{~d}$ at a constant temperature $\left(25^{\circ} \mathrm{C}\right.$; author's unpubl. data). The von Bertalanffy growth function (VBGF) parameter, $K$, was estimated for each temperature dataset from the length $\left(L_{t}\right)$ taken at each time measurement, $t$ :

$$
L_{t}=L_{\infty}\left(1-\mathrm{e}^{-K\left(t-t_{0}\right)}\right)
$$

This model also includes terms for the age at which length is zero, $t_{0}$, and the asymptotic body length, $L_{\infty}$. Initially, VBGFs were developed for each temperature dataset by Berry (1987) using nonlinear leastsquares estimation for all 3 parameters. A second set of $K$ values was estimated for each temperature using constant values of $t_{0}$ and $L_{\infty}$ that were derived from fish growth over $653 \mathrm{~d}$ at $25^{\circ} \mathrm{C}$. Comparison of modeled growth projections at each temperature using varying values of $t_{0}$ and $L_{\infty}$ yielded unrealistically large $1 \mathrm{~d}$ fish at lower temperatures as a result of extremely low $t_{0}$. Growth projections using constant and realistic values of $t_{0}(-10.14)$ and $L_{\infty}(5.78 \mathrm{~cm})$ most closely matched the measured data and yielded more realistic estimates for young fish. Therefore, $t_{0}$ and $L_{\infty}$ were held constant and simulations only included a temperature-dependent model of $K$, which had good fit with measured data; however, where empirical data are not available to calibrate temperature growth models, varying $t_{0}$ and $L_{\infty}$ with temperature should be explored. The values of $K$ at each temperature, $T$, were fit to a logistic function such that (Fig. 2a):

$$
K(T)=0.013 /\left(1+\mathrm{e}^{(T-19.9) /-5.01}\right)
$$

This function is used to determine the duration of mobile life stages at a simulated temperature. The transition size of larvae to juvenile $(1.5 \mathrm{~cm})$ and juvenile to adult $(2.6 \mathrm{~cm})$ determined the duration of the mobile immature stages. At each temperature, $K(T)$ determines the size of fish at each day post hatch from 1 to $800 \mathrm{~d}$, and the stage duration is the number of days within the size range of each stage. The model does not track individuals from days post hatch, but uses the number of days within each stage to approximate the duration of the larval and juvenile stages at a given temperature. Adult life stage was held constant at $365 \mathrm{~d}$, which began at sizes $>2.6 \mathrm{~cm}$. 

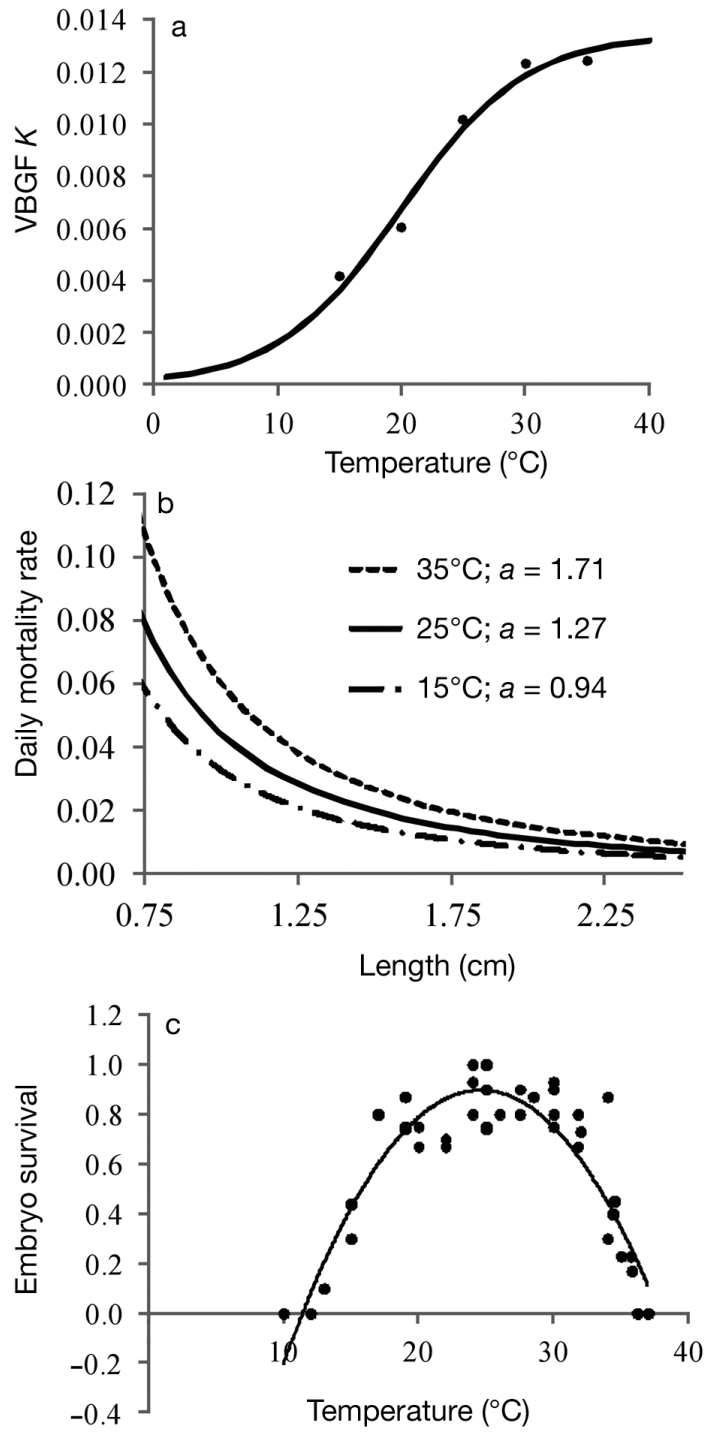

Fig. 2. Cyprinodon variegatus. (a) The relationship between the von Bertalanffy growth function (VBGF) constant $K$ and temperature fit to a logistic function (curve). The data points represent values of $K$ derived from sheepshead minnow growth at various temperatures (from Berry 1987). (b) The relationship between daily mortality rate and length at various temperatures and values of the parameter a (Eq. 4). (c) The relationship between embryo survival and temperature (from Kinne \& Kinne 1962)

The relationship between body size and mortality has been modeled using several different types of functions, but the power function has been previously identified as a well-suited relationship for small estuarine fish (Munch et al. 2003). A power function was developed that models the direct effects of both size and temperature on daily mortality, $M$, for each discrete length determined by $K(T)$, such that:

$$
M\left(L_{t}\right)=a m_{1} L_{t}^{m_{2}}
$$

The parameter $a$ is a temperature-dependent scaling factor that describes increased mortality with temperature resulting from extraneous ecological factors, such as predation. An exponential function was used here based on the relationship between temperature and predator consumption rate (Buckel et al. 1995) and is:

$$
a=0.6 \mathrm{e}^{0.03 T}
$$

This function was parameterized by iteratively selecting values to result in a value of 1 at the median temperature of $17^{\circ} \mathrm{C}$ and had an arbitrary range of approximately 0.8 and 1.7 that increased with temperature. The parameter $m_{1}$ is the mortality at the unit length of $1 \mathrm{~cm}$, and $m_{2}$ is the allometric exponent that describes the negative relationship of size to mortality. Values of $m_{1}(0.035)$ and $m_{2}(-2.0)$ were obtained by calibrating the model $\left(a=1\right.$, temperature $\left.=17^{\circ} \mathrm{C}\right)$ so the annual mortality rates for young of year (larvae + juveniles) and adults were 0.99 and 0.54 , respectively, as suggested for cyprindontid fishes (Abraham 1985). This mortality function assumes independence between $a$ and $m_{2}$ (Fig. 2b). Stage-specific survival probability at each temperature, $p_{i}(T)$, is determined as:

$$
\begin{aligned}
& p_{i}(T)=P\left[\text { survival from time } t_{0} \text { to } t_{1}\right]= \\
& \exp \left[-\int_{t_{0}}^{t_{1}} M\left(L_{t}\right) \mathrm{d} t\right]
\end{aligned}
$$

\section{Seasonal reproduction}

The sheepshead minnow experiences seasonal reproduction that ranges from shortened breeding seasons in the northern part of its range to yearround breeding in the south (Nelson 1992, Nordlie 2000). De Vlaming et al. (1978) found no seasonal influence on sheepshead minnow fecundity based on gonadal somatic indices; however, Kinne \& Kinne (1962) found significant relationships between temperature and both embryo incubation and survival. To incorporate seasonal changes in the survival of the embryo stage, a quadratic function was derived from estimates of embryo mortality at various temperatures presented by Kinne \& Kinne (1962; Fig. 2c). For model simulations, a lower bound of zero was set to avoid survival rates below that limit that may be predicted by the quadratic equation. The duration of the embryo stage provided by Kinne \& Kinne (1962) was modeled as $\ln$ (duration) $=67.3 T^{-1.1}$. Stage durations determined from this function, as well as those determined for larvae and juveniles, were rounded to whole numbers. 


\section{General population model}

The basis of the population model is the deterministic, density-independent stage-based matrix model of Caswell (2001). This model allows each life stage to be explicitly described in terms of survival $\left(P_{i}\right)$, transition $\left(G_{i}\right)$, and reproductive potential $\left(F_{i}\right)$ as:

$$
\boldsymbol{A}=\left[\begin{array}{cccc}
P_{1} & 0 & F_{3} & F_{4} \\
G_{1} & P_{2} & 0 & 0 \\
0 & G_{2} & P_{3} & 0 \\
0 & 0 & G_{3} & P_{4}
\end{array}\right]
$$

The model has a $5 \mathrm{~d}$ time step corresponding to the shortest duration of embryo stage, with the population growth rate $(\lambda)$ estimated from the dominant eigenvalue of the matrix. Since model parameters are derived from the temperature-dependent functions described above, the effective model is:

$$
A(T)=f\left[P_{i}(T), G_{i}(T), F_{i}(T)\right]
$$

and the resulting population growth rate is $\lambda(T)$. For simplicity, the parameterization of the model that is described below does not include the notation of temperature dependency.

Matrix parameters are estimated from the stagespecific duration and survival described above. Duration of each stage at each temperature is incorporated in the model through $\tau_{i}$ which is the number of model time steps within each life stage (e.g. if the duration of a life stage is $20 \mathrm{~d}$, the $5 \mathrm{~d}$ time step results in $\tau_{i}=4$ ). First, the lower-order probability that an individual will survive within a model time step is described as:

$$
\sigma_{i}=p_{i}^{\frac{1}{\tau_{i}}}
$$

The lower-order probability of transitioning to the next stage within the time step is (Caswell 2001):

$$
\gamma_{i}=\frac{\left(\frac{\sigma_{i}}{\lambda}\right)^{\tau_{i}}-\left(\frac{\sigma_{i}}{\lambda}\right)^{\tau_{i}-1}}{\left(\frac{\sigma_{i}}{\lambda}\right)^{\tau_{i}}-1}
$$

An iterative approach is used to estimate $\gamma_{i}$ using $\lambda$ by setting an initial value of $\lambda$ to 1 and recalculating parameters until the input value of $\lambda$ converges with that of the resulting matrix. This assumes a stable size distribution within each life stage, in which the largest individuals graduate to the next stage and smaller individuals move up a size class within the stage. Survival and development probabilities of each stage within a time step are then calculated as $P_{i}=\sigma_{i}\left(1-\gamma_{i}\right)$ and $G_{i}=\sigma_{i} \gamma_{i}$. It should be noted that when $\tau_{i}$ is equal to 1 (i.e. duration of life stage is equal to the model time step), $\gamma_{i}$ is equal to $1, P_{i}$ is 0 , and all surviving individual transitions to the next life stage as described by $G_{i}=\sigma_{i}$. For the adult life stage, $\gamma_{i}$ and $G_{i}$ are equal to 0 and $P_{i}=\sigma_{i}$.

Reproduction during a time step is determined from the birth-flow model of Caswell (2001) in which the total number of new recruits to Stage $1\left(F_{3+4}\right)$ is a function of the average number of eggs produced per female within the $5 \mathrm{~d}$ time step, $m$, and the proportion of surviving adults and transitioning juveniles and is:

$$
F_{3+4}=\left(P_{1}+G_{1}\right)^{\frac{1}{2}}\left(\left[1+P_{4}\right] m+G_{3} m\right) \cdot N_{f}
$$

where $N_{f}=0.365$ is the fecund proportion of the population, assuming a 50:50 sex ratio modified by the proportion of adult females with eggs (0.73) collected from wild populations (author's unpubl. data). The value of $m$ is 203, based on the average daily egg production measured in the seawater controls of Cripe et al. (2009) and adjusted by the difference in fecundity (90\%) between field-collected and laboratory-reared sheepshead minnow (author's unpubl. data).

\section{Model simulations}

Matrix model parameters are calculated for each integer temperature ranging from 10 to $35^{\circ} \mathrm{C}$. Model development for temperatures $<10^{\circ} \mathrm{C}$ is confounded by unrealistically long life-stage durations (e.g. $>350 \mathrm{~d}$ ), increasing the uncertainty in model parameter estimation using the discrete approximation of mortality. Sheepshead minnow burrow at temperatures $<10^{\circ} \mathrm{C}$, presumably to maintain body temperatures above their lower physiological limit (Bennett \& Beitinger 1997), so the model assumes that populations exposed to environmental temperatures $<10^{\circ} \mathrm{C}$ are approximated by the dynamics at that minimum temperature.

Average monthly temperatures for 16 estuaries from Texas to Maine were obtained from the NOAA's National Ocean Service tidal stations (www.nodc. noaa.gov/dsdt/cwtg/, accessed 12 September 2011, Table S1 in the supplement at www.int-res.com/ articles/suppl/m469p101.xls). For each estuarine system, 4 simulations were conducted: one used seasonal variations and the others used constant parameters representing the lower, median, and upper quartile temperature for each location. Population projections using seasonal variation were based on the model parameters derived for monthly mean temperature, using a value of $10^{\circ} \mathrm{C}$ for months when 
average temperatures were $<10^{\circ} \mathrm{C}$. Simulations ran for a 24 mo period beginning in April, with an initial population of 1000 individuals distributed among stages according to the stable stage distribution identified by Raimondo et al. (2009).

\section{Sensitivity analysis}

The model contains several assumptions relating to fish growth, maturation, stage duration, sizedependent mortality, and temperature-dependent mortality. A global sensitivity analysis was conducted to identify the importance of primary parameter estimates to $\lambda$ and to evaluate the potential impacts of parameter uncertainty. The primary parameters $\left(K(T), m_{1}, m_{2}\right.$, a, embryo stage duration, embryo stage survival, eggs per day, larva-juvenile maturation size, juvenile-adult maturation size, and adult stage duration) were altered simultaneously through Monte Carlo simulation, which randomly drew parameters from $\pm 20 \%$ of the value observed at the median temperature of $17^{\circ} \mathrm{C}$ for 1000 iterations. Modifying values simultaneously allows the importance of interactions among model parameters as they relate to $\lambda$ to be assessed; however, the independent, random variation of each parameter does not account for biological covariation of terms. The sensitivity, $s_{X}$, of $\lambda$ to each parameter, $x$, was determined using the regression method of Yoshie et al. (2007) in which:

$$
s_{X}=\frac{\Delta \lambda(x) / \Delta x}{\lambda\left(x_{0}\right) / x_{0}}
$$

where $\lambda\left(x_{0}\right)$ and $x_{0}$ are the values of $\lambda$ and $x$ in the baseline run and $\Delta \lambda(x) / \Delta x$ is the slope of the linear regression of the altered values of population growth rate, $\lambda(x)$, versus altered $x$-values for all iterations.

\section{RESULTS}

The logistic model defining the value of $K(T)$ for each temperature predicts values $<0.002$ at temperatures $<10^{\circ} \mathrm{C}$, indicating a near or complete cessation of growth at these temperatures (Fig. 2a). Growth rate increases between 10 and $35^{\circ} \mathrm{C}$, after which it tends toward an asymptote. Based on embryo stagespecific survival and duration functions modeled from Kinne \& Kinne (1962), $P_{1}$ decreases with increasing $G_{1}$, with $P_{1}$ approaching zero as the duration of the stage approaches the time step, resulting in $G_{1}$ equal to stage-specific survival (Fig. 3a). Stagespecific survival of larvae and juveniles increases with temperature as a function of increased growth rate, which subsequently increases transition probability, $G_{i}$ (Fig. 3b,c). The increase in larval survival probability, $P_{2}$, with temperature coincides with the slowest increase in $G_{2} . P_{2}$ decreases as more larvae transition to juveniles, as indicated by a concurrent increase in $G_{2}$ (Fig. 3b). $P_{3}$ is relatively stable across all temperatures, decreasing slightly with increasing $G_{3}$ and temperature (Fig. 3c). The values of $\lambda$ for the simulated temperatures $\left(10\right.$ to $\left.35^{\circ} \mathrm{C}\right)$ range from 0.99 to 1.59 (Fig. 4). Values $<1$ occur where fecundity is zero and larval survival is $<0.001$. Maximum population growth rate is at $30^{\circ} \mathrm{C}$, and declines as temperature increases above this value. Table S2 in the
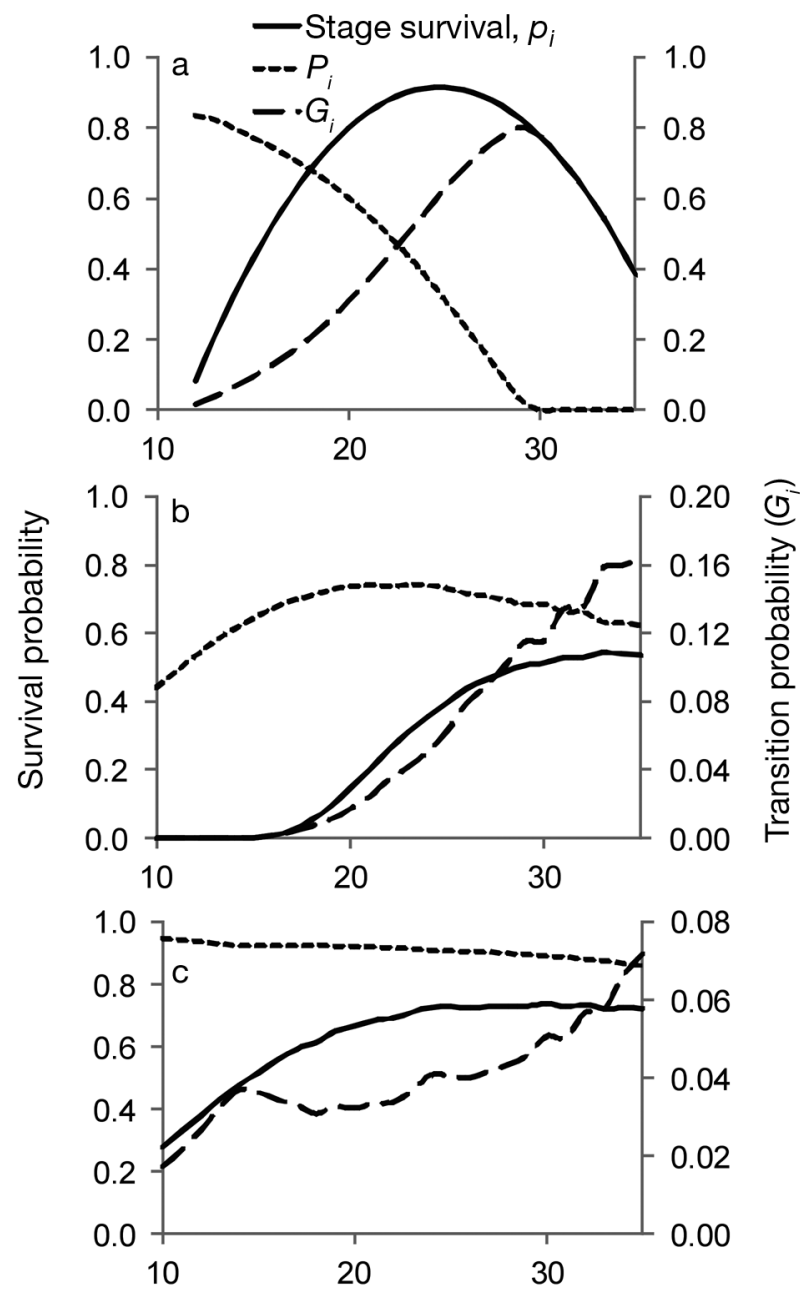

Temperature $\left({ }^{\circ} \mathrm{C}\right)$

Fig. 3. Cyprinodon variegatus. Relationship of temperature to stage-specific survival ( $p_{i}$ i black solid line), survival $\left(P_{i i}\right.$ dashed line, short intervals), and transition $\left(G_{i}\right.$ i dashed line, long intervals) for (a) embryos, (b) larvae, and (c) juveniles. $G_{i}$ is plotted on the secondary $y$-axis 


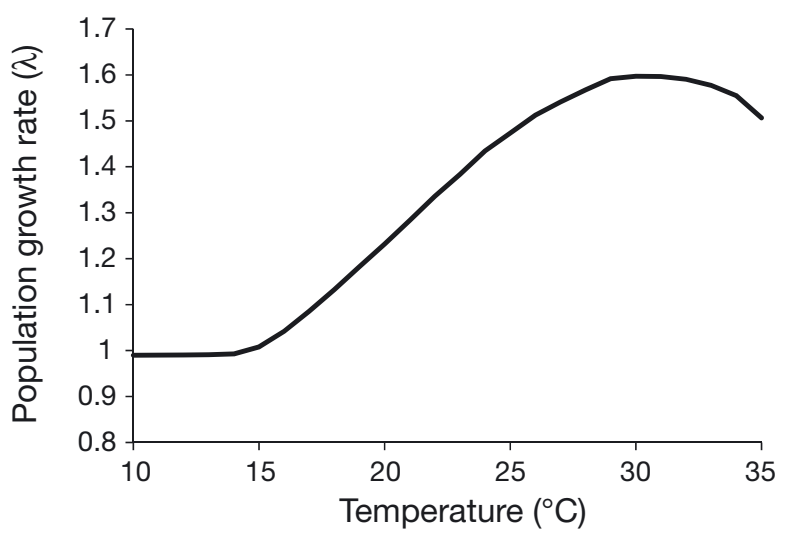

Fig. 4. Cyprinodon variegatus. Relationship of temperature and population growth rate $(\lambda)$

supplement at www.int-res.com/articles/suppl/m469 p101.xls provides all temperature-dependent model parameters.

Adult population size projections using seasonal and constant parameters vary with latitude throughout the geographic range. Population projections at the northern-most sites (e.g. Portsmith Harbor, New
Hampshire; Boston, Massachusetts) decline using median and lower quartile parameter values, while populations subject to the upper quartile parameter values increase. Projections using temperaturevarying parameters have non-linear population projections, including a decrease in growth during colder time steps (Fig. 5a). Mid-Atlantic sites (e.g. Kiptopeke, Virginia; Myrtle Beach, South Carolina) also have declining populations using lower quartile parameter values, with seasonal projections between the upper and median quartile projections (Fig. 5b,c). Projections using seasonal and median parameters are indistinguishable for populations in the southernmost site in Miami Beach, Florida (Fig. 5d).

Sensitivity analysis of temperature-dependent model parameters indicates that $K(T)$ is the most important parameter predicting $\lambda$. The sensitivity of $\lambda$ to the variables influencing the temperature-mortality relationship, $a_{1} \mathrm{~m}_{1}$ and $\mathrm{m}_{2}$, and juvenile to adult maturation size are the next highest, although they are considerably lower than $K(T)$. The sensitivity of the model outcome is low for other natural-history parameters (Table 1).
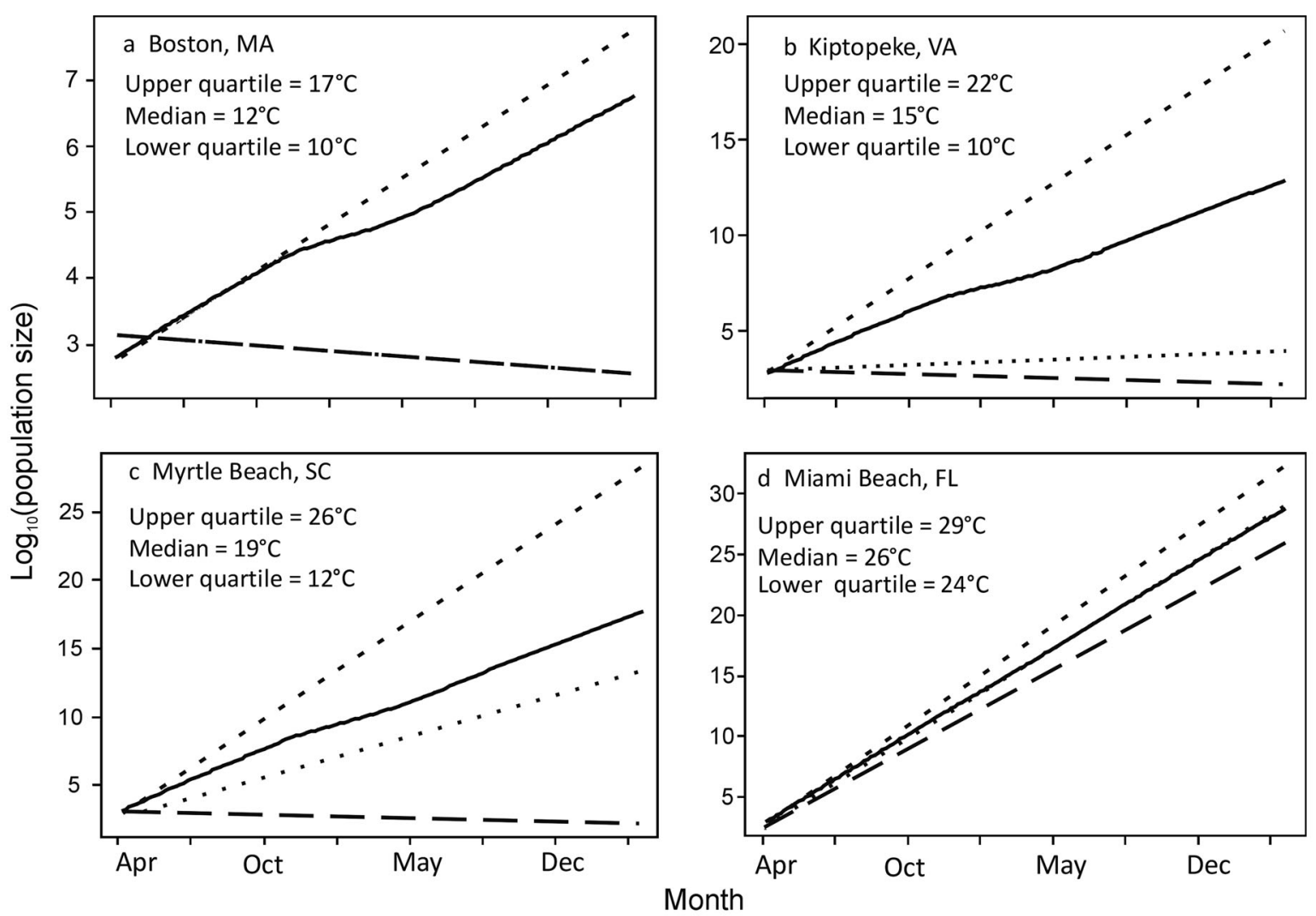

Fig. 5. Cyprinodon variegatus. Two-year population projections using seasonal variations in parameters (solid lines) and upper (short-dashed lines), median (dotted lines), and lower quartile (long-dashed lines) parameter values for (a) Boston, Massachusetts; (b) Kiptopeke, Virginia; (c) Myrtle Beach, South Carolina; and (d) Miami Beach, Florida 
Table 1. Cyprinodon variegatus. Sensitivity values of model parameters. See 'Methods' for parameter definitions

\begin{tabular}{|lc|}
\hline Parameter & Sensitivity \\
\hline$K$ & 0.638 \\
$a$ & 0.104 \\
Juvenile-adult maturation size & 0.076 \\
$m_{2}$ & 0.058 \\
$m_{1}$ & 0.056 \\
Eggs per day & 0.004 \\
Embryo stage duration & 0.003 \\
Embryo stage survival & 0.003 \\
Adult stage duration & $<0.001$ \\
Larval-juvenile maturation size & $<0.001$ \\
\hline
\end{tabular}

\section{DISCUSSION}

Conservation and management decisions that employ population models are complicated by the trade-offs of realism, generality, and parsimony. The inclusion of seasonal variations in demographic rates increases the realism of population models, but is generally lacking in application for fish management despite its well-documented occurrence (Post \& Parkinson 2001, Shoji \& Tanaka 2007, Buckley et al. 2010). The model presented here incorporates temperature-driven growth rate, mortality, and reproduction for a small fish species, Cyprinodon variegatus, and is used to compare projections using seasonally varying and constant parameters. Sensitivity analysis determined VBGF $K(T)$ as the most important parameter determining $\lambda$, with model parameters and the size of juvenile maturation as the next most important variables, although considerably less so. Other characteristics of the species natural history had minor influences on model outcome.

The high sensitivity of $\lambda$ to $K(T)$ is consistent with the tenet that size and the amount of time an individual stays in a vulnerable size class are the primary drivers of natural mortality in fishes (Griffiths \& Harrod 2007). Hoenig (1983) proposed that longevity alone could predict natural mortality through an inverse relationship consistent with the seasonal model presented here. The prediction of reproductive age in Great Lakes fishes modeled with stageexplicit expressions of VBGF validates the approach of defining life-stage duration by $K(T)$ for field populations (He \& Stewart 2002). In the absence of direct temperature effects on mortality (a), larger values of $K(T)$ yield shorter stage duration and lower stagespecific mortality. This is consistent with other studies concluding intra-specific variations in growth rate yield lower mortality with faster growth (Rice et al.
1993, Meekan \& Fortier 1996, Hare \& Cowen 1997, Takasuka et al. 2004, Durieux et al. 2009, Meekan et al. 2006).

The sensitivities of $\lambda$ to juvenile to adult maturation size, $a, m_{1}$, and $m_{2}$ were the next highest, albeit considerably less than $K$, while the sensitivity of $\lambda$ was very low for other life-history parameters. These results demonstrate the relative importance of submodel selection and calibration. In the model presented here, the power function (Eq. 3) was selected based on its application in overwinter survival of fish of different sizes (Munch et al. 2003). Other sizerelated survival models that have a similar relationship of survival and size include exponential functions (Pepin 1991), Beverton-Holt invariants (Jensen 1996), and multiple regressions (Pauly 1980, Djabali et al. 1993, Gislason et al. 2010); although these are typically used for inter-species comparisons. The parameters $m_{1}$ and $m_{2}$ were calibrated using only 2 values for stage-specific survival (Abraham 1985). While a more desirable approach would be to calibrate the model using a well-populated dataset that empirically demonstrates the relationship between survival and size, these data rarely exist for most species. Most importantly, model calibration should use field-derived survival rates when possible. The parameter a (Eq. 4) was included in the model to represent the increase in fish mortality with temperature that results from extraneous ecological factors, such as predation (Buckley et al. 2010). Although little information is available to quantify this relationship and the model used here was adjusted to an arbitrary range of values, it was included so the sensitivity of $\lambda$ to additional environmental influences could be assessed. The low value produced by the sensitivity analysis suggests that the value and function of $a$ are less important than the temperature-growth and size-mortality submodels, but has more influence on model outcome than other life-history parameters. While ample data were available for this species for some submodels (e.g. temperature-growth rate, temperature-embryo development), many functions were developed using minimal data and assumptions. In general, data availability will be variable, and often limited, for most species. The application of models should include the caveat that the predicted outcome is only as good as the data that inform the submodels and include an evaluation of the associated uncertainty.

Inclusion of data-derived relationships of growth rate and temperature with regard to site specificity for a species of concern is critical to reduce uncertainty in the $K(T)$ function. Counter-gradient varia- 
tion in growth rate, in which populations at higher latitudes have a genetic propensity toward faster growth than at lower latitudes, is well documented for many species (Conover \& Present 1990, Conover et al. 1997). The data used here to develop the temperature- $K$ relationship (Fig. 2a) are based on growth using populations from both Pensacola Bay, Florida, and Narragansett Bay, Rhode Island, and did not show an inverse relationship between growth rate and latitude of the parental generation (Berry 1987). While a counter-gradient in growth rate was not included here and may not be applicable to all species, using the $K$-temperature relationship determined for specific populations would alleviate the need for additional spatial considerations. Beyond the influences of seasonality or latitude, site-specific differences in demographic parameters attributed to other factors (e.g. habitat) should also be considered.

The work presented here provides a method for which seasonal variations in demographic measurements are translated to reproduction and survival probabilities, and uses the stage-based matrix model as a demonstration. Matrix models may also be ageor size-based; however, the stage-based approach is often preferred because it allows users to construct a model that reflects the biological structure of the life cycle. The modeling approach demonstrated here would be simplified considerably for adaption to ageor size-based models. Using the stage-based model illustrates how survival and transition within and between cohorts is a function of temperature-based models, and would be consistent across modeling constructs. These basic patterns could also be used to inform processes within IBMs, if they were preferred.

In fish, transitioning to the next life stage may be determined by size, age, or both depending on the species (Kuparinen et al. 2011). The model presented here assumes that life-stage transition is size dependent based on observations for this species (Cripe et al. 2009). More complex functions that define stage transitions by multiple thresholds will propagate uncertainty in the transition probabilities using the stage-based model. For species where complex transition functions are desirable, more flexible models such as IBMs may be more appropriate. An additional caveat for using the stage-based matrix model, as parameterized here, is that the derivation of $\lambda$ assumes a stable size distribution within each life stage (Caswell 2001), which is slightly different for each simulated temperature as the number of transitioning individuals changes with $K(T)$. This does not affect the state-based estimation of $P_{i}, G_{i}$, or $\lambda$, which are based on static conditions, but may result in a time-step lag in transition probabilities during projection simulations. It should be noted that this uncertainty is present whenever a periodic, stage-based model is used to project populations in changing environments, such as those exposed to pollutants or climate change (e.g. André et al. 2010). This effect can be minimized by applying a model time step that is shorter than the temporal resolution of the environmental variability.

Seasonal variation in the production of offspring is affected by fecundity, embryo survival, stage duration, and juvenile maturation size. Of these variables, $\lambda$ was only moderately sensitive to juvenile maturation size. In the sensitivity analysis, a $\pm 20 \%$ change in the number of eggs produced per female did not have a large influence on $\lambda$, but the cessation of reproduction results in $\lambda<1$ and consequent population declines. Seasonal reproduction and embryo development for this species are highly variable with latitude (Hardy 1978, Nelson 1992, Pattillo et al. 1997, Nordlie 2000); however, with a geographic range that extends through Maine, this species is capable of reproducing where average monthly temperatures may only exceed $15^{\circ} \mathrm{C}$ a few months a year. The temperature-embryo model used here predicts reproduction occurring above $12^{\circ} \mathrm{C}$, which corresponds with average monthly temperatures in the northern part of its range from June through September (Table S1 in the supplement). This model also concurs with the optimal embryo development temperature of 22 to $29^{\circ} \mathrm{C}$ (Pattillo et al. 1997), at which embryo survival is between 80 and $90 \%$ and corroborates with estimates for field embryo survival (Abraham 1985). While these seasonal reproduction functions reflect the trends of embryo production and survival for this species, the number of eggs per female and seasonally varying functions for embryo stage duration and survival appear to have little influence on model outcome at temperatures $>12^{\circ} \mathrm{C}$. As such, seasonal reproduction may be simplified to only reproduce above a threshold temperature in this case.

Simulations of density-independent population projections showed that seasonal parameters produce considerably different trajectories than constant rates throughout the species' range, except at the southern-most site. Simulations indicate that exclusion of the principle seasonal effect, reduced growth, and cessation of reproduction in winter months, could result in considerable error in population estimation over many years. The relationship of seasonal model projections to those based on upper quartile and median parameters varies by latitude for this 
species, but this effect may be different for species exhibiting counter-gradients of growth rate and latitude (Conover \& Present 1990). Regardless, comparison of seasonal and constant projections at different latitudes supports the need to incorporate seasonal variability in parameters at all latitudes except in those for the southern-most regions.

This research suggests that demographic parameters should not be held constant for fisheries models. In addition to the temporal variation modeled here, there may be local variation in demography within an estuarine system (Griffiths \& Harrod 2007, Lanier \& Scharf 2007). The relative impact of $K(T)$ and temperature-driven mortality (e.g. a) may be difficult to isolate in natural systems and may potentially be folded into one mechanism to simplify a model of seasonal variability. However, their separation in this model provides increased utility for application in situations where growth and survival are independently influenced by additional mechanisms such as density dependence (Marschall \& Crowder 1995, Lorenzen \& Enberg 2002) or toxicant exposure (Logan 1986).

Fisheries management and conservation need to continue developing approaches that incorporate realism into models in such a way as to reduce uncertainty. The model presented here uses a case study of a single species to demonstrate the uncertainty associated with using constant or annual demographic rates for modeling populations. It includes seasonal functions for all life stages, but identified temperature-dependent growth rate as the most critical factor to incorporate into models to capture seasonal variability for this species. A more parsimonious version of this model could limit seasonal variation in growth rate and an 'on-off' function of reproduction, providing a simpler alternative to including a fecundity submodel. While the overall modeling framework presented here is a valid approach to incorporate seasonal variability of temperature into population projections, the distribution of $\lambda$ and its connection to variable temperatures is limited by the information available for the submodels, as well as assumptions of the density-independent stage-based model construct. While a model incorporating seasonal variation for other fish species may require additional functions, this model provides a framework that may be tailored to other species or model constructs (e.g. IBMs) to reduce uncertainty where models are applied in fisheries conservation and management.

Acknowledgements. Thanks to Susan Yee, Hannah Rutter, Michael Norberg, Jill Awkerman, Richard Fulford, Mace Barron, and Matthew Etterson. The views expressed in this paper are those of the author and do not necessarily reflect the views or policies of the U.S. Environmental Protection Agency. This is Contribution Number 3328 from the Gulf Ecology Division.

\section{LITERATURE CITED}

Abraham BH (1985) Species profiles: life histories and environmental requirements of coastal fishes and invertebrates (Mid-Atlantic) - mummichog and striped killifish. US Fish Wildlife Service Biological Report 82 (11.40), US Army Corps of Engineers, TR EL-82-4, Washington, DC

Anderson JT (1988) A review of size dependent survival during pre-recruit stages of fishes in relation to recruitment. J Northwest Atl Fish Sci 8:55-66

André J, Haddon M, Pecl GT (2010) Modelling climatechange-induced nonlinear thresholds in cephalopod population dynamics. Glob Change Biol 16:2866-2875

$>$ Bennett WA, Beitinger TL (1997) Temperature tolerance of the sheepshead minnow, Cyprinodon variegatus. Copeia 1997:77-87

Berry WJ (1987) Aspects of the growth and life history of the sheepshead minnow, Cyprinodon variegatus, from Rhode Island and Florida. PhD thesis, University of Rhode Island, Kingston, RI

> Bevacqua D, Melia P, Leo GAD, Gatto M (2011) Intraspecific scaling of natural mortality in fish: the paradigmatic case of the European eel. Oecologia 165:333-339

> Brunton BJ, Booth DJ (2003) Density- and size-dependent mortality of a settling coral-reef damselfish (Pomacentrus moluccensis). Oecologia 137:377-384

> Buckel JA, Steinberg ND, Conover DO (1995) Effects of temperature, salinity, and fish size on growth and consumption of juvenile bluefish. J Fish Biol 47:696-706

Buckley LJ, Lough RG, Mountain D (2010) Seasonal trends in mortality and growth of cod and haddock larvae result in an optimal window for survival. Mar Ecol Prog Ser 405:57-69

> Carlson SM, Olsen EM, Vollestad LA (2008) Seasonal mortality and the effect of body size: a review and an empirical test using individual data on brown trout. Funct Ecol 22:663-673

Caswell H (2001) Matrix population models. Sinauer Associates, Sunderland, MA

Conover DO, Present TMC (1990) Countergradient variation in growth rate: compensation for length of the growing season among Atlantic silverside from different latitudes. Oecologia 83:316-324

Conover DO, Brown JJ, Ehtisham A (1997) Countergradient variation in growth of young striped bass (Morone saxatilis) from different latitudes. Can J Fish Aquat Sci 54: 2401-2409

Cowan JH Jr, Houde ED, Rose KA (1996) Size-dependent vulnerability of marine fish larvae to predation: an individual based-numerical experiment. ICES J Mar Sci 53: 23-37

> Cripe GM, Hemmer BL, Goodman LR, Fornie JW and others (2009) Multigenerational exposure of the estuarine sheepshead minnow (Cyprinodon variegates) to 17aestradiol. I. Organism-level effects over three generations. Environ Toxicol Chem 28:2397-2408

> de Vlaming VL, Kuris A, Parker FR Jr (1978) Seasonal variation of reproduction and lipid reserves in some subtropical cyprinodontids. Trans Am Fish Soc 107:464-472 
Djabali F, Mehailia A, Koudil M, Brahmi B (1993) Empirical equations for the estimation of natural mortality in Mediterranean teleosts. Naga ICLARM Q Fishbyte 16:35-37

> Dobson ADM, Finnie TJR, Randolph SE (2011) A modified matrix model to describe the seasonal population ecology of the European tick Ixodes ricinus. J Appl Ecol 48: 1017-1028

> Durieux EDH, Meekan MG, Ponton D, Vigliola L (2009) Temperature, selective mortality and early growth in the short-lived clupeid Spratelloides gracilis. J Fish Biol 74: 921-938

Etterson MA, Bennett RS, Kershner EL, Walk JW (2009) Markov chain estimation of avian seasonal fecundity. Ecol Appl 19:622-630

Gislason H, Daan N, Rice JC, Pope JG (2010) Size, growth, temperature and the natural mortality of marine fish. Fish Fish 11:149-158

Griffiths D, Harrod C (2007) Natural mortality, growth parameters, and environmental temperature in fishes revisited. Can J Fish Aquat Sci 64:249-255

Hansen DJ, Parrish PR (1977) Suitability of the sheepshead minnows (Cyprinodon variegatus) for life-cycle toxicity tests. In: Mayer FL, Hamelink JL (eds) Aquatic toxicology and hazard evaluation. American Society for Testing and Materials, Philadelphia, PA

Hardy JJD (1978) Development of fishes of the Mid-Atlantic Bight, Book 3. Center for Environmental and Estuarine Studies, Solomons, MD

Hare JA, Cowen RK (1997) Size, growth, development, and survival of the planktonic larvae of Pomatomus saltatrix (Pisces: Pomatomidae). Ecology 78:2415-2431

$>$ He JX, Stewart DJ (2002) A stage-explicit expression of the von Bertalanffy growth model for understanding age at first reproduction of Great Lakes fishes. Can J Fish Aquat Sci 59:250-261

Hewitt DA, Hoenig JM (2005) Comparison of two approaches for estimating natural mortality based on longevity. Fish Bull 103:433-437

Hoenig JM (1983) Empirical use of longevity data to estimate mortality rates. Fish Bull 82:889-903

> Islam MS, Ueno M, Yamashita Y (2010) Growth-dependent survival mechanisms during the early life of a temperate seabass (Lateolabrax japonicus): field test of the 'growthmortality' hypothesis. Fish Oceanogr 19:230-242

> Jensen AL (1996) Beverton and Holt life history invariants result from optimal trade-off of reproduction and survival. Can J Fish Aquat Sci 53:820-822

> Kinne O, Kinne EM (1962) Rates of development in embryos of the cyprinodont fish exposed to different temperature-salinity-oxygen combinations. Can J Zool 40: 231-253

Kuparinen A, Arias JMC, Loehr J, Herczeg G, Gonda A, Merila J (2011) Fish age at maturation is influenced by temperature independently of growth. Oecologia 167: 435-443

> Lanier JM, Scharf FS (2007) Experimental investigation of spatial and temporal variation in estuarine growth of age-0 juvenile red drum (Sciaenops ocellatus). J Exp Mar Biol Ecol 349:131-141

> Letcher BH, Horton GE (2008) Seasonal variation in sizedependent survival of juvenile Atlantic salmon (Salmo salar): performance of multistate capture-mark-recapture models. Can J Fish Aquat Sci 65:1649-1666

> Levin LA, Huggett DV (1990) Implications of alternative reproductive modes for seasonality and demography in an estuarine polychaete. Ecology 71:2191-2208

> Logan DT (1986) Use of size-dependent mortality models to estimate reductions in fish populations resulting from toxicant exposure. Environ Toxicol Chem 5:769-775

> Lorenzen K (1996) The relationship between body weight and natural mortality in juvenile and adult fish: a comparison of natural ecosystems and aquaculture. J Fish Biol 49:627-647

Lorenzen K, Enberg K (2002) Density-dependent growth as a key mechanism in the regulation of fish populations: evidence from among-population comparisons. Proc Biol Sci 269:49-54

Marschall EA, Crowder LB (1995) Density-dependent survival as a function of size in juvenile salmonids in streams. Can J Fish Aquat Sci 52:136-140

McCoy MW, Gillooly JF (2008) Predicting natural mortality rates of plants and animals. Ecol Lett 11:710-716

Meekan MG, Fortier L (1996) Selection for fast growth during the larval life of Atlantic cod Gadus morhua on the Scotian Shelf. Mar Ecol Prog Ser 137:25-37

Meekan MG, Vigliola L, Hansen A, Doherty PJ, Halford A, Carleton JH (2006) Bigger is better: size-selective mortality throughout the life history of a fast-growing clupeid, Spratelloides gracilis. Mar Ecol Prog Ser 317: 237-244

Miller TJ, Crowder LB, Rice JA, Marschall EA (1988) Larval size and recruitment mechanisms in fishes: toward a conceptual framework. Can J Fish Aquat Sci 45:1657-1670

Morris JA Jr, Shertzer KW, Rice JA (2011) A stage-based matrix population model of invasive lionfish with implications for control. Biol Invasions 13:7-12

Munch SB, Mangel M, Conover DO (2003) Quantifying natural selection on body size from field data: winter mortality in Menidia menidia. Ecology 84:2168-2177

Nelson DM (1992) Distribution and abundance of fishes and invertebrates in Gulf of Mexico estuaries, Vol 1: data series. ELMR Rep. No. 10, NOAA/NOS Strategic Environmental Assessments Division, Rockville, MD

Nordlie FG (2000) Patterns of reproduction and development of selected resident teleosts in Florida salt marshes. Hydrobiologia 434:165-182

Pattillo ME, Czapla TE, Nelson DM, Monaco ME (1997) Distribution and abundance of fishes and invertebrates in Gulf of Mexico estuaries, Vol II. Species life history summaries. ELMR Rep. No. 11, NOAA/ NOS Strategic Environmental Assessments Division, Silver Spring, MD

Pauly D (1980) On the interrelationships between natural mortality, growth parameters, and mean environmental temperature in 175 fish stocks. J Cons Int Explor Mer 39: 175-192

> Pepin P (1991) Effect of temperature and size on development, mortality, and survival rates of the pelagic early life history stages of marine fish. Can J Fish Aquat Sci 48: 503-518

> Post JR, Parkinson EA (2001) Energy allocation strategy in young fish: allometry and survival. Ecology 82: 1040-1051

Raimondo S, Hemmer BL, Goodman LR, Cripe GM (2009) Multigenerational exposure of the estuarine sheepshead minnow (Cyprinodon variegates) to 17 a-estradiol. II. Population-level effects through two life cycles. Environ Toxicol Chem 28:2409-2415

> Rice JA, Miller TJ, Rose KA, Crowder LB, Marschall EA, Trebitz AS, DeAngelis DL (1993) Growth rate variation and larval survival: interferences from an individual- 
based size-dependent predation model. Can J Fish Aquat Sci 50:133-142

Rowe CL, Dunson WA (1995) Individual and interactive effects of salinity and initial fish density on a salt marsh assemblage. Mar Ecol Prog Ser 128:271-278

Savage VM, Gillooly JF, Brown JH, West GB, Charnov EL (2004) Effects of body size and temperature on population growth. Am Nat 163:429-441

Shoji J, Tanaka M (2007) Growth and mortality of larval and juvenile Japanese seaperch Lateolabrax japonicus in relation to seasonal changes in temperature and prey abundance in Chikugo estuary. Estuar Coast Shelf Sci 73:423-430

Takasuka A, Aoki I, Mitani I (2004) Three synergistic

Editorial responsibility: Alejandro Gallego,

Aberdeen, UK growth-related mechanisms in the short-term survival of larval Japanese anchovy Engraulis japonicus in Sagami Bay. Mar Ecol Prog Ser 270:217-228

Thompson JM, Bergersen EP, Carlson CA, Kaeding LR (1991) Role of size, condition, and lipid content in the overwinter survival of age-0 Colorado squawfish. Trans Am Fish Soc 120:346-353

Warlen SM (1964) Some aspects of the life history of Cyprinodon variegatus Lacepede, 1803, in southern Delaware. MSc thesis, University of Delaware, Newark, DE

Yoshie N, Yamanak Y, Rose KA, Eslinger DL, Ware DM, Kishi MJ (2007) Parameter sensitivity study of the NEMURO lower tropic level marine ecosystem model. Ecol Modell 202:26-37

Submitted: December 16, 2011; Accepted: August 6, 2012 Proofs received from author(s): November 7, 2012 